\title{
RAVES AND ECSTASY USE IN EGYPT: A SUBCULTURAL PARADIGM
}

\author{
Nashaat H. Hussein
}

Misr International University Misr, Egypt

\begin{abstract}
This article aims to investigate the main aspects of the growing subculture of ecstasy (MDMA) users in Egypt. It criticizes post-modern theoretical orientations that devalue subcultural theories of deviance on the basis that they can no longer support an understanding of recreational substance use among youth today. Through ethnography and semi-structured interviews and observation, the social and subcultural use of the recently introduced psychoactive substance ecstasy is examined. Data reveals that ecstasy use takes place within a broader glocal subculture of drug use. A main conclusion from the data is that understanding the etiology of ecstasy use in Egypt needs a thorough understanding of its related youth subculture.
\end{abstract}

KeY WorDs: Ecstasy; raves; ethnography; subculture; glocalization

\section{INTRODUCTION}

Early attempts to study illicit substance use among youth revealed that it took place primarily in deviant subcultures (Cohen, 1955; Miller, 1958; Becker, 1963; Parker, 1974). Therefore, subcultural theories of deviance took precedence and became the leading theories to explain the etiology and motivations of illicit substance use among youth. They emphasized the importance and relevance of deviant subcultures to the instigation and continuation of deviant behaviors, and asserted that deviance is the result of learning and acquirement of values and norms within the context of a subculture, that may contradict with those of the mainstream culture.

Critics, particularly post-modernists(Malbon, 1998; Miles, 1998; Bennett, 1999; Muggleton,
2000; Chaney, 2004), argue that subcultural theories of deviance can no longer offer accurate or coherent explanations of the etiology and prevalence of contemporary illicit substance use among youth, especially with regard to raving or clubbing. Subcultural theories, from the post-modernists' perspective, fail to highlight personal or individual motivations for substance use. They believe that subcultural theories need to be replaced by other theoretical orientations and concepts such as 'youth lifestyles' or 'neotribes' (Readhead, 1997; Bennett, 1999; Miles, 2000). Bill Sanders (2006), for example, asserts that "conceptualizations of 'subculture' do not capture raving or clubbing" (Sanders, 2006: 3). Post-modernists also identify individualist rather than collectivist patterns of substance use as a missing element in the subcultural theories

Corresponding author: Nashaat H. Hussein, PhD, Assistant Proefessor, Mass Communication \& Alsun Department, Misr International University, Cairo, Egypt 
of deviance and emphasize that they usually ignore or underestimate individual sensation, intoxication, and self-satisfaction. To them, new forms of self-expression manifest themselves in contexts where illicit substances and different types of dance music allow young people to implode with the pure joy of individualistic consumption (Blackman, 2004).

Rave and club substance use, from their perspective, are seen as a group gathering or an event that is less structured and more diverse in its relationships, but not mainly a reflection of a growing deviant subculture, since consumerism allows young people to construct alternative lifestyles through local and global strategies where in local settings they can use (Shuerkens, 2003). Accordingly, the basic components of a subculture like shared sentiments, values, behavioral patterns, and mores need to be reassessed since they ignore changes in personal orientations and tastes, and mainly exhibit substance users as mere constructed products of group socialization. These recent trends have raised doubt as to whether illicit substance use among youth still takes place within a subcultural context.

In fact, the way post-modernists propose an alternative theoretical orientation to explain deviant behavior does not offer a coherent explanation to several inquiries concerning illicit substance use among youth. Illicit substance use usually entails involvement in social networks that guide the user on which substances to consume, how and when to consume them, and the risk factors involved in his/ her drug habit. Understanding the effect of the illicit substance consumed entails a learning process that cannot be achieved solely at the individual or personal level (Hussein, 1990), while defining the effect of an illicit substance, like ecstasy, as 'pleasurable' is a learning process that entails membership in an ecstasy-use subculture (Gourley, 2004). On the other hand, subcultural theories of deviance allow space for individual variations in illicit substance use since they recognize that while shared values and norms contrary to conventional society serve to define such groups, group cohesion or organization may differ substantially between or among different subcultures (Clinard \& Meier, 1992). "Many individuals, for example, may belong to more than one deviant subcultural group at a time" (Finley, 2007: 266-267). Therefore, subcultural theories of deviance do not limit individual drug behavior to a specific subcultural setting, but rather allow individualization, even within a single subcultural context.

Despite post-modernists' alternative outlook, contemporary research on illicit substance use among youth still emphasize the existence of a subcultural context of deviance. For example, Tracy Shildrick (2006) in her study of Youth culture, subculture and the importance of neighborhood concluded that "subcultural theories still have some pertinence in understanding some contemporary youth cultural experiences" (Shildrick, 2006: 64). Consequently, post-modernists' rejection of the roles of learning and subcultural membership weakens methodical discernment of the illicit substance use phenomenon among youth.

This article aims to investigate the main aspects of the growing subculture of ecstasy (MDMA) users in Egypt. It criticizes the postmodern theoretical orientation that debases subcultural theories of deviance, and argues that the recently introduced psychoactive substance prevails among a segment of Egyptian youth within a glocal subcultural context of raves and ecstasy use. As a global phenomenon, the local-global dynamism resulted in a 'glocalized' subculture, with its distinctive values, modes of behavior, and norms. Reasons for selecting ecstasy for this study include its relative recency to the Egyptian society, and lack of relevant local research on its basic consumption patterns. A main conclusion from the study is that understanding the etiology of ecstasy use in Egypt needs a thorough understanding of its related deviant youth subculture. The research begins with an overview of the history of raves and ecstasy use in Egypt, which resulted in the initiation of an ecstasy subculture among Egyptian users. The second part discusses the process by which local users contributed to a growing glocalized account of Western ecstasy subculture owing 
to the interaction between local and global dimensions. The last part highlights the major aspects of the ecstasy use subculture as expressed by the interviewees.

\section{METHOD}

The present research used ethnography as a main methodological orientation. Techniques of data collection included semi-structured and structured observations and in-depth interviews. Sample recruitment was based on the 'network sampling technique' to reach a nonrandom purposeful sample of twenty respondents, half of which are males and the rest are females. Respondents in the present research were young adults aging 18-23 (median=20.4). Ages of the male group ranged between 18 and 23 (median=21), and between 19 and 21 for the female group (median=19.8).

Sample scanning revealed a number of shared characteristics among the respondents. The entire sample reported education at a college level, being single, and holders of the Egyptian nationality. Surprisingly, only 10\% of the respondents indicated signs of family breakdown, parental divorce, and separation, which refers to the existence of other factors that typically lead to their drug habit. Interviews occurred at the time and location agreed upon by the respondents. A thematic analysis of the data was made to understand the coinciding conceptions of risk among youth. Quotations in the paper are meant to provide descriptive evidence of these thematic patterns across the interviews and represent general attitudes revealed by the respondents. All illustrations are derived from the in-depth interviews.

\section{INITIATION OF THE ECSTASY SUBCULTURE IN EGYPT}

A subculture can be defined as "a distinctive set of standards and behavioral patterns by which a group within the larger society operates" (Haviland et al., 2007: 152). It is a secondary group within society that exhibits a shared pattern of values which varies from the culture and impacts on the individuals that belong to it (Lenartowicz \& Roth, 2001), and is perceived as a segment of society that shares distinguishing values, knowledge and behavior that differ and possibly conflict with the dominant mainstream culture (Chang \& Chuang, 2005). Accordingly, a subculture develops on the basis of shared ideas, values, beliefs, and practices among a group of people within the larger society.

Early subcultural theorists attempted to explain the factors that contribute to the emergence of deviant subcultures. Albert Cohen (1955), for instance, showed that deviant subcultures initiate when people realize that they are deprived of their rights. In his study of how delinquent subcultures emerge, he showed that lack of opportunities and resources among lower-class boys help in the emergence of a deviant subculture among them. Others like Walter Miller (1958) criticized Cohen's strain theory, and explained that the beliefs and practices of lower-class boys are seen as reflecting their original adult lower-class culture, and that delinquent youth subcultures do not necessarily invert middle-class norms but dominant cultural patterns of the characteristics of the socio-economic class to which they belong. Conversely, Howard Parker (1974) revealed that youth can develop their own deviant subculture in ways that do not inflect class-based characteristics. He showed that youth elaborate on the existing cultures of earlier generations, and create their own distinctive modes of behavior through cultural innovation.

Despite these theoretical guidelines, interviews with ecstasy users in Egypt revealed a different subcultural initiation model. All respondents claim that the ecstasy use subculture first emerged in Egypt during the early 1990s when rave parties (the main construction where ecstasy is used) were held and propagated mainly among wealthy or upper-class youth. These findings contradict with the previously discussed theories of deviant subcultures, especially with Cohen's strain theory, and also contradict with the available literature on the demographic characteristics of Western ravers, in 
which a rave is commonly perceived as a form of middle-class youth partying (Avis, 1999; Fritz, 1999; Reynolds, 1999; Weir, 2000; Wilson, 2006; Gourley, 2004; Hunt et al., 2010).

Findings also correlate with the data available from a research carried out on the most widely used illicit substances among youth in poor and squatter areas in Cairo, which indicated that cannabis (93.8\%), Parkinol (42.7\%), cough medicine $(22.3 \%)$, volatiles $(39.4 \%)$, alcoholism (19.4\%), opiates (6.6\%), Maxiton Forte $(4.3 \%)$, and heroin $(2.8 \%)$ are the typical substances consumed by youth in underprivileged areas (El-Nayal, 2002: 124). None of the respondents revealed that ecstasy (MDMA) is used among poor youth. Prevalence of ecstasy use in Egypt appeared in the Ecstasy and Amphetamines Global Survey of the United Nations Office on Drugs and Crime (2003), which indicated that "amphetamine-type stimulants (ATS) manufacture is limited to a few cases in a few countries, especially Egypt and South Africa" (UNODC, 2003: 22). In another recent report, UNODC revealed that "a case of attempted ecstasy manufacture occurred in Alexandria-Egypt in 2004" (UNODC, 2008: 79), which refers to the existence of a clandestine market for amphetamine-type stimulants, particularly ecstasy, in Egypt.

Unlike typical Western raves, early recognition and proliferation of rave parties, along with their associated patterns of ecstasy consumption, occurred predominantly among upper-class youth who found in raves an alternative form of youth celebration that is distinct from other modes of popular youth festivities. Historical development of raves in Egypt also indicates that when they first started they were somewhat covert or underground, and that parties were mostly organized or attended by closed networks of upper-class friends or acquaintances who shared similar ideas and interests about the uniqueness of raves, believed in the distinctiveness of the event as an exotic and a fashionable form of youth celebrations, and accepted the idea as a unique experience.

Interviews revealed that youth were motivated to consume ecstasy when they realized that their friends and peers consume the substance in rave or music parties. They also emphasized that knowledge and identification of new types of Western music (like Techno, Trance, Metal, etc.) and understanding the effects of the corresponding recreational drugs (Reynolds, 1999; Weir, 2000; Holland, 2001) have gradually associated with their unique identity and personal status, which helped in creating their distinctive persona and accelerated the diffusion of similar ideas among them. Being a clandestine activity similar to raves in Britain and the United States (Forsyth \& Bernard, 1997), raves were confined to a certain segment of upper class youth during its early initiation period, which facilitated the dissemination of misconceptions about the relationship between Techno-music (commonly played in raves) and ecstasy use among them, and that ecstasy enhances the rave party and Techno-music experiences. Uniqueness of rave parties, the profits gained by club promoters, and the distinctive persona of the gathering contributed to the success of early raves and resulted in a wider propagation of the idea among other strata of youth during the second half of the 1990s. Although raves were only limited to certain closed-networks of friends and acquaintances in the beginning, diffusion of raves to include a wider segment of the youth population has helped in the emergence and formation of a distinctive local ecstasy subculture, as a respondent explains:

\section{Instead of being hidden and limited to particular networks of friends, rave par- ties began to take a different direction. Parties held in the late 1990s were orga- nized in certain venues where thousands of youth either organized or attended them. During the late 1990s, ravers be- came a special group with special char- acteristics.}

Accordingly, participation of various strata of Egyptian youth in music parties and ecstasy use helped in reshaping the class-based persona of the gathering and marked the beginning of a new subcultural formation that is based on the context where they meet and interact together. 
The rave-ecstasy experience resulted in the construction of distinct shared ideas, values, and behavioral patterns among the users.

\section{DISTINCTIVENESS OF EGYPTIAN RAVES: A GLOCALIZED MODEL}

There is no doubt that the rave-ecstasy culture first emerged in the West as a typical Western youth phenomenon, which later spread to the rest of the world. Understanding that once a cultural element is accepted into a new culture it may undergo changes in form or function to conform to the new culture, the typical Western rave culture was not identically replicated by youth in Egypt, who conversely developed their own distinctive rave fashions, ecstasy-related paraphernalia and patterns of ecstasy use.

Various culture-specific boundaries resulted in a global-local dynamic process that can be referred to as 'glocalization.' Glocalization can be defined as "the interpenetration of the global and local, resulting in unique outcomes in different geographic areas" (Ritzer \& Atalay, 2010: 319). It is essentially a hybrid of globalization and localization (Mendis, 2007; Chew, 2009). In this sense, glocalization theoretically challenges the previously influential paradigm of cultural imperialism, which denotes that local populations literally adopt global waves of change and replicate them in local settings.

Despite the fact that the local ecstasy subculture grew in an urban environment as part of urban lifestyles in a way similar to typical Western raves (Fritz, 1999), interviews revealed that words like 'raves' or 'dancing parties' are never mentioned in any partying promotion messages utilized. Several culturalspecific boundaries hinder the widespread usage of the word 'raves' in the society and force both club-promoters and ravers to come up with new culturally accepted vocabulary in order to evade socio-cultural restrictions. Terms like 'music parties' (or just 'parties') are regularly used to refer to raves, as a 20 -year-old respondent explains:
The word 'rave' is never used because when translated into Arabic it means 'hazayan' or 'hawas' (ramble or crazy parties). The word may drive the attention of our parents or others to the types of parties we attend, and they may prevent us from attending them.

Although most youth try to resemble Western ravers in their dancing styles and fashions, various local-based limitations have been described by the interviewees to differentiate local ravers from their counterparts in the West, especially with regard to ecstasy-related paraphernalia commonly used in Western raves. Most respondents argue that appreciation of Western raves does not mean a similar appreciation of their associated ecstasy- related paraphernalia to be replicated in local settings, as one explains:

I cannot walk in the streets with colorful dies on my hair. It would be embarrassing if my parents knew that I do that. However, we do this just before the party begins. After the party, we wash and return back to normal. Even when I use ecstasy, I only use it during the party, knowing that its effect only lasts for the duration of the event.

Understanding the illegality of the activity, refusal of club-promoters to accept or normalize ecstasy use by the attendees, and out of practicality, an interviewer reveals his thorough understanding of Western raves if compared to local raves, and that only certain drug-related items are considered suitable for local ecstasy use:

Few ravers can be seen wearing items like sunglasses at night or carrying glowsticks during raves. Not all Western paraphernalia is used. Wearing baby's pacifiers, for example, would stigmatize those who use them by the attendees and friends. Once under ecstasy's effect, one can overcome teeth clenching by chewing gum, which would not drive the attention of the 
attendees. Other items like nasal inhalers and surgical masks would immediately expose us to a problem since everyone would recognize that we are under the effect of ecstasy, and we may get expelled from the whole scene by club promoters.

These remarks indicate that although ecstasy users accepted the rave/ecstasy culture as a global phenomenon, they modified its prototypical components to include local-based ideas and practices due to various cultural boundaries. Glocalization, in this sense, resulted in a new global-local form of ecstasy subculture that promoted ecstasy use among youth.

\section{BASIC ASPECTS OF THE ECSTASY SUBCULTURE}

Although ecstasy users in Egypt share many similar characteristics, they do not represent a homogenous social group. Nevertheless, they have developed their own subculture that sets them apart from other emerging forms of youth subcultures. Various shared ideas, values, norms, sentiments, and drug-related behavioral patterns have been expressed by the respondents, which represent the main features of their idiosyncratic subculture. To investigate the basic components of their subculture, an attempt was made to assess the etiological bases of the their drug-habit, their shared ideas concerning the risk factors associated with ecstasy use, and their knowledge and ability to identify a person under ecstasy's effect in rave and music parties.

Table (1) refers to the main reasons for ecstasy use, as expressed by the sample. Examining the etiology of their drug-habit revealed that $(95 \%)$ of ecstasy users comprehend that there is a direct link between ecstasy and techno-music. They explained that taking ecstasy enhances their appreciation of the music, and provides them with enough energy to dance for hours. On the other hand, $(80 \%)$ of the sample indicated that sensation seeking, happiness, and euphoria mainly associate with their ecstasy use. The music, the vibe, the atmosphere,
Table 1. Reasons for ecstasy use among youth $(\mathrm{n}=20)$

\begin{tabular}{lc}
\hline Reason & $(\mathbf{\% )}$ \\
\hline Ecstasy enhances the rave experience & $19(95)$ \\
Sensation seeking, happiness \& euphoria & $16(80)$ \\
Not an addictive drug & $15(75)$ \\
Establishing friendship in parties & $13(65)$ \\
Easy to use drug & $9(45)$ \\
To escape problems & $2(10)$ \\
\hline
\end{tabular}

and the state of mind ecstasy produces seem to be determining factors in their drug-habit. They also assert that they learned how to feel the effect of the drug consumed through their contact with friends and peers in rave and music parties. These findings correspond to the subcultural theories of deviance, which indicate that learning and understanding how to use the drug properly and feel its effect happen within a broader subcultural context that develops among users of that particular drug (Cohen, 1955). A respondent explains how he learned about the effect of ecstasy in music parties by stating:

To know the effect of the drug, you need to have friends at the party who can tell you later how you behaved after the party is over. One of my friends told me before the party that ' $e$ ' would make me happy. He told me how friendly I was to others.

Further investigation revealed that other shared ideas or (mis)conceptions justify using ecstasy. For instance, there is a widely accepted notion among $(75 \%)$ of the respondents that ecstasy is not addictive, if compared to other harder drugs like heroin or cocaine. This commonly disseminated misconception represents a major component of their subculture, and perhaps a leading factor for their ecstasy use since it motivates and encourages party-goers to try ecstasy, at least on a recreational basis. Although many scholars emphasize that ecstasy use "involves a high risk of dependence, as regular abusers in most cases seem to be unwilling to quit" (Lintner, 2001: 182), most 
of the sample interviewed stressed that ecstasy is only limited to the music parties they attend, and asserted that they never use the drug when they are alone. Ecstasy users also claim that sustained heavy use of ecstasy is rare, partly because it is impractical to continue taking ecstasy at an older age. Consequently, very few become addicted to it, as one reveals:

$E$ (for ecstasy) is only for young people. It matches with their age. Old people do not do this. They will be stigmatized. They usually consume other drugs and not ' $e$ '.

Ecstasy, as expressed by (65\%) of the sample, is only enjoyable when used in groups along with peers and friends in raves or music parties. These findings strongly suggest that ecstasy use is a group-orientated activity and that there is a norm in the ecstasy use pattern which entails that "one does not use the drug alone" (Gourley, 2004: 63). According to them, ecstasy and partying help users make new friends, and that through being together in a rave, they can get to know each other better since they do the same things. Although local users did not state that openly, there is a widely accepted conception among Western ravers that ecstasy is a "hug-drug that promotes loving feelings" (Burns, 2007: 131), which facilitates making new friends. In other words, similar ideas and misconceptions derived from Western raves have been disseminated through the rave movement to different parts of the globe including local users. However, their interpretation seems to be subjected to local standards that hindered the proliferation of similar ideas at the local level. On the other hand, $(45 \%)$ of the sample claimed that ecstasy is easy to use, if compared to other types of drugs that require certain preparations or apparatuses like hashish or opium, while only $(10 \%)$ of the sample have tried ecstasy to escape their personal hardships and the psychological stresses involved.

Subcultural theories of deviance usually refer to the development of an argot or a special language among members of one subculture (Gelder, 2007). Similarly, interviews revealed that ecstasy users have developed their own argot, which is a clear manifestation of their subculture, as a respondent shows:

Ecstasy is commonly known as the 'e' or
'belaia' (a pill). A person under ecstasy's
effect is usually called makhbout (hit by
the drug), or dareb (under ecstasy's ef-
fect). We also use glow-sticks for vasuala
(an Arabic translation for visualization)
to see colorful visions that enhance the
techno-music experience.

Most of the sample interviewed reported knowledge of the risk factors involved in their drug habit, which also refer to their involvement in a common subculture. Risk factors, as expressed by $(95 \%)$ of the sample (Table 2 ), include increased heart rate and blood pressure at an alarming rate (that can be very dangerous for youth with cardiac diseases). Interviews also revealed that $(80 \%)$ of the respondents are aware that drug dealers may mix ecstasy with other substances to increase their profit, and that some of these substances may be toxic, which increases their vulnerability, as one explains:

You can get poisoned or die if you get a forged pill, or an overdose. Many dealers fool young attendees and convince them that they sell ' $e$ ', where in fact they sell sedatives.

Also, $(65 \%)$ of the sample stated that ecstasy is a 'gateway' for the consumption of other harder drugs. The psychological state of mind it produces and its regular habitual use may motivate users to consume other drugs to have similar experiences or sustained effect, as a respondent explains:

I know many friends who started with ' $e$ ' and ended up being poly-drug users. I know that 'e' is a gateway for using other harder drugs.

Other risk factors explained by the sample included their knowledge that ecstasy use may 
lead to suppression of the body's thermo-regulatory system and putting users at risk of dehydration and overheating (60\%), and depression $(55 \%)$, since the disappearance of the drug's effect from the body always leads to what they identified as a 'crash', as one shows:

The hardest part is the 'crash'. It makes me feel like crazy and unable to think for hours. I usually become depressed.

Risk factors also included fatigue (40\%), involuntary teeth clenching (35\%), and nausea, blurred visions, faintness, chills and sweating $(20 \%)$. Conversely, when the interviewees were asked about the withdrawal symptoms associated with quitting, they reported mild hangover periods of melancholy and woolly headedness that usually last for a few days, which refer to their shared knowledge of its negative effects and withdrawal symptoms.

In order to identify a person under ecstasy's effect in music parties, respondents argue that they usually rely upon their shared knowledge of the physical symptoms connected with ecstasy use, as well as their knowledge of its paraphernalia. Physical symptoms, from their perspective, include gaining a sudden extraordinary energy $(90 \%)$ that allows users to dance hysterically for hours, constant eye staring $(75 \%)$, teeth clenching $(60 \%)$, and extreme dehydration through excessive sweating and heating (45\%). A respondent

Table 2. Risk factors of ecstasy use among youth $(\mathrm{n}=20)$

\begin{tabular}{lc}
\hline Reason & $(\mathbf{\%})$ \\
\hline Increased heart rate \& blood pressure & $19(95)$ \\
Poisoning & $16(80)$ \\
Ecstasy is a gateway for other & $13(65)$ \\
$\quad$ harder drugs & \\
Dehydration and overheating & $12(60)$ \\
Depression related to withdrawal & $11(55)$ \\
$\quad$ symptoms & $8(40)$ \\
Fatigue & $7(35)$ \\
Teeth clenching & $4(20)$ \\
Nausea and blurred vision & \\
\hline
\end{tabular}

Table 3. Identification of a person under ecstasy's effect $(n=20)$

\begin{tabular}{lc}
\hline Indicator & $(\mathbf{\%})$ \\
\hline Sudden extraordinary energy & $18(90)$ \\
Eye staring & $15(75)$ \\
Teeth clenching & $12(60)$ \\
Excessive sweating \& dehydration & $9(45)$ \\
\hline
\end{tabular}

explains how he identifies a person under ecstasy by saying:

\begin{abstract}
When a person becomes makhbout (with a 'high' in ecstasy), hel she suddenly becomes energetic and begins to dance violently and relentlessly for hours without stopping. Eyes get wide open in a scary way. Teeth clench to the extent that one may bite his/ her own tongue. With excessive sweating and heating, a person usually consumes large amounts of water.
\end{abstract}

\section{CONCLUSION}

The goal of this research was to investigate the main aspects of the growing subculture of ecstasy use in Egypt. The study suggests that ecstasy users have developed their own distinctive subculture that centers mainly on their drug habit, and that ecstasy use occurs predominantly within an ecstasy-using subculture.

Findings criticize the assumption of postmodernists that subcultural theories of deviance can no longer support solid understandings of the means and motivations of youth towards substance use, and that subcultural theories need to be replaced by other growing post-modernist trends that relate the etiology of substance use among youth to individual motivations, and discredit explaining substance use within a socializing - learning subcultural environment. Findings from the present study, however, reveal that shared beliefs, norms, and behavioral patterns have been identified among ecstasy users. These shared ideas, sentiments, and values represent, according to the respondents, the basic foundations for their 
ecstasy use since they entail going through a learning process of how and when to consume ecstasy and learn its effect.

Data from the present study also reveal that although ecstasy use initiated mainly among wealthy upper-class youth, participation of other strata of Egyptian youth in the activity helped in reshaping or reconstructing the ecstasy use subculture among them. Findings suggest that cultural borrowing of deviant Western ideas by Egyptian youth does not occur instantaneously, but normally goes through a process of modification supported by a subcultural formation to make those ideas applicable to local schemes. Despite the invariable variations between Egyptian youth and the global youth culture, ecstasy users have simply mitigated Western waves through a process of glocalization to suit their local demands. Ecstasy users have developed their own idiosyncratic local-based ecstasy-rave subculture with its values, norms, and paraphernalia that favor and support their ecstasy habit.

A main conclusion from the study is that it is essential to understand that there is a global constituent involved in local drug trends that typically result in a glocalized model of consumption. It is also important to comprehend that ecstasy use takes place within a subcultural context of deviance in which peer groups, peer pressure, and imitation of friends and peers motivate adolescents and youth to initiate their drug habits, even if at a recreational basis. Although ecstasy use takes place within the boundaries of raves and music parties, there is still a major role played by learning within a subcultural context of how to use and feel the effect of the drug.

\section{REFERENCES}

Avis, H. (1999). Drugs and Life. New YorK: McGraw-Hill.

Becker, H. (1963). Outsiders: Studies in the Sociology of Deviance. New York: Free Press.

Bennett, A. (1999). Subcultures or Neo-tribes: Rethinking the Relationship between Youth, Style and Musical Taste, Sociology 33(3): 599-617.
Blackman, S. (2004). Chilling Out: The Cultural Politics of Substance Consumption, Youth and Drug Policy. London: Open University Press.

Burns, M. (2007). Medical-Legal Aspects of Drugs. Arizona: Lawyers \& Judges Publishing Company.

Chaney, D. (2004). Fragmented culture and subcultures, in A. Bennett \& K. KahnHarris (Eds.), After subculture: Critical studies in contemporary youth culture. Basingstoke, UK: Palgrave.

Chang, L. \& Chuang, H. (2005). The Study of Subculture and Consumer Behavior: An Example of Taiwanese University Students' Consumption Culture, Journal of the American Academy of Business 7(2): 258-64.

Chew, M. (2009). Cultural Localization and its Local Discontents: Contested Evaluations of Cantopop Electronic Dance Music, in Kwok-bun, Chan et al. (Eds.) Social Stratifications in Chinese Societies. Leiden: Koninklijke Brill.

Clinard, M. \& Meier, R. (1992). Sociology of Deviant Behavior. Fort Worth, TX: Harcourt Brace Jovanovich College Publishers.

Cohen, A. (1955). Delinquent Boys: The Culture of the Gang. Glencoe: Free Press.

El-Nayal, H. (2002) Drug Consumption: Factors and Dynamics, in Drug Use among Youth in Squatter Areas: A Field Research in Sharabia (in Arabic). Cairo: Studies of the National Center for Social and Criminal Research Fund for the Control and Treatment of Addiction and Abuse, pp. 105 - 146.

Finley, L. (2007). Encyclopedia of Juvenile Violence. West Port, CT: Greenwood Press.

Forsyth, A. \& Barnard, M. (1997). Musical Preference as an Indicator of Adolescent Drug Use, Addiction 92 (10): 1317 - 1325.

Fritz, J. (1999). Rave Culture: an Insider's Overview. Canada: Small-Fry Press.

Gelder, K. (2007). Subcultures: Cultural Histories and Social Practice. Oxon: Routledge Publications.

Gourley, M. (2004). A Sub-cultural Study of Recreational Ecstasy Use, Journal of Sociology Vol. 40 (1) 59-73. 
Haviland, W., Prins, H., Walrath, D. \& McBride, B. (2007). The Essence of Anthropology. CA: Thompson Wadsworth.

Holland, J. (2001). Ecstasy: The Complete Guide. Vermont: Park Street Press.

Hunt, G., Moloney, M. \& Evans, K. (2010). Youth, Drugs, and Night Life. Oxon: Routledge Publications.

Hussein, N. (1990). The Sub-Culture of Hashish Users in Egypt: A Descriptive Analytic Study, Cairo Papers in Social Science, vol. 13 , no. 2 .

Lenartowicz, T. \& Roth, K. (2001). Does Subculture within a Country Matter? A Crosscultural Study of Motivational Domains and Business Performance in Brazil, Journal of International Business Studies 32(2): 305-25.

Lintner, E. (2001). Germany: A Strict Approach, in Wilson H (Ed.) Drug, Society, and Behavior. Connecticut: McGraw-Hill.

Malbon, B. (1998). Clubbing: Consumption, Identity and the Spatial Practices of Every-Night Life, in G. Valentine, T. Skelton and D. Chamber (eds.) Cool Places: Geographies of Youth Cultures. London: Routledge.

Mendis, P. (2007). Glocalization: the Human Side of Globalization as if the Washington Consensus Mattered. New York: Lulu Press.

Miles, S. (1998). Consumerism as a Way of Life. London: Sage Publications.

Miles, S. (2000). Youth Lifestyles in a Changing World. Milton Keynes: Open University Press.

Miller, W. (1958). Lower Class Culture as a Generating Milieu of Gang Delinquency, Journal of Social Issues 14(3): 5-19.
Muggleton, D. (2000). Inside Subculture: The Postmodern Meaning of Style. Oxford: Berg.

Parker, H. (1974). View from the Boys: A Sociology of Down-town Adolescents. Newton Abbot: David and Charles.

Redhead, S. (1997). The Club-cultures Reader: Readings in Popular Cultural Studies. Oxford: Blackwell.

Reynolds, S. (1999). Generation Ecstasy: Into the World of Techno and Rave. Culture Boston: Little, Brown \& Company.

Ritzer, G. \& Atalay, Z. (2010). Readings in Glocalization: Key Concepts and Major Debates. Oxford: Blackwell Publishing.

Sanders, B. (2006). Drugs, clubs, and Young People: Sociological and Public Health Perspectives. Hampshire: Ashgate Publishing.

Schuerkens, U. (2003). Social Transformations between Global Forces and Local Life-Worlds: Introduction, Current Sociology, 51: 195.

Shildrick, T. (2006). Youth Culture, Subculture, and the Importance of Neighborhood. Young, Vol. 14(1): 61-74.

UNODC (2003). Ecstasy and Amphetamines: A Global Survey. Vienna: UNODC Publications.

UNODC (2008). Amphetamines and Ecstasy: 2008 Global ATS Assessment. Vienna: UNODC Publications.

Weir, E. (2000). Raves: A Review of the Culture, the Drugs, and the Prevention of Harm, Canadian Medical Association Journal, 162: 1843-1849.

Wilson, B. (2006). Fight, flight, or chill: Subcultures, youth, and rave into the 21st century. Montreal \& Kingston: McGillQueen's University Press. 